\title{
Simulation Based-Learning from Simple to Complicated Clinical Situations for Midwifery Students
}

\author{
Omaima Changuiti (D) \\ Nawar Moustarhfir (D) \\ Abdelghafour Marfak (iD) ${ }^{1,2}$ \\ Elmadani Saad (D) ${ }^{\prime}$ \\ Abderraouf Hilali ${ }^{\prime}$ \\ Ibtissam Youlyouz- \\ Marfak (D)
}

'Hassan First University of Settat, Higher Institute of Health Sciences, Laboratory of Health Sciences and Technologies, Settat, 26000, Morocco; ${ }^{2}$ National School of Public Health, Rabat, 10000, Morocco

Correspondence: Ibtissam YoulyouzMarfak

Hassan First University of Settat, Higher Institute of Health Sciences, Laboratory of Health Sciences and Technologies, Settat, 26000, Morocco

$\mathrm{Tel}+212661604358$

Fax +212523400187

Email ibtissam.marfak@uhp.ac.ma
Purpose: A health professional's learning curriculum should lead to the acquisition of technical and non-technical skills. This study aims at demonstrating the impact of simulation-based learning (SBL) experience on the learning of midwifery students.

Patients and Methods: Using an experimental design, the experimental group $(n=14)$ received pretest, high fidelity simulation, then a post-test. Whereas the control group $(n=14)$ received pretest, revision of the theoretical course instead of simulation, post-test 1 , high fidelity simulation, then a post-test 2 . The first scenario was about a normal childbirth when the midwifery students were in their 2 nd year. And then the second one was about immediate postpartum hemorrhage when the students moved to their 3rd year.

Results: During the simulation sessions, the experimental group had a higher mean score in the post-test than the control group. This indicated that the simulation significantly $(p<0.001)$ increased the students' knowledge. Also, for both eutocic and dystocic delivery simulation experiments, students obtained higher score in the second simulation sessions (19.69 and 19.4 for eutocic and dystocic, respectively) than in the first session (11.23 and 9.12 for eutocic and dystocic, respectively; $\mathrm{p}<0.0001$ ).

Conclusion: These findings confirm that SBL offers an opportunity for learners to be immersed in an environment that is closer to reality, thus improving learning in a safe environment.

Keywords: postpartum hemorrhage, midwifery, high fidelity simulation, training, curriculum, obstetric

\section{Introduction}

The initial training of midwives in Morocco lasts three years. At the end of the degree program, midwifery students are given a diploma that allows them to practice midwifery in both public and private health structures. Midwives are primarily responsible for the delivery process. Due to complications related to pregnancy and childbirth, approximately 830 women die every day worldwide. Postpartum hemorrhage is one of the leading causes of maternal mortality, accounting for $25 \%$ of maternal deaths worldwide. ${ }^{1}$ The increasing maternal mortality rate, notably in developing countries is a challenge for health systems. Indeed, developing countries are promoting and prioritizing the reduction of maternal mortality ${ }^{2}$ considering it as one of the eight Millennium Development Goals (MDGs). In this context, Morocco has made significant progress in reducing the maternal mortality rate by $35 \%$ from 112 deaths (2009-2010) to 72 (2015-2016) per 100,000 live 
births. This health problem, which can transform a happy event (childbirth) into tragic loss, requires effective collaboration between researchers, physicians, nurses and citizens. Health educators, especially midwifery professors are concerned by the maternal mortality. Health institutes, training and preparing future midwives, are the first door to knock and are the first task to tackle towards a major and effective change providing a solid and up-to-date training to the young graduates aspiring for a better new future.

To promote learning for midwifery students, it is recommended to adopt an effective pedagogical approach such as a simulation-based learning (SBL) experience. ${ }^{3}$ It is defined by Meakim et al as a realistic situation in a simulated environment ${ }^{4}$ where learners are at liberty to make mistakes and learn from them, thus gaining a deeper understanding of the consequences of their actions and the need to "get it right". 5

SBL is a crucial learning modality for midwifery education. ${ }^{6}$ During the last two decades, SBL is recognized as an essential training approach engulfing both theory and practice to profit by the positive and fruitful outcomes of each one. It has been demonstrated that SBL contributes widely to the reduction of lethal medical errors that take innocent women's lives, an approach that allows students to broaden their knowledge, sharpen their practice so as to gain and acquire the necessary competences to avoid deleterious collateral damage on future patients. ${ }^{7}$ Burns et al affirmed that SBL allows midwifery students to improve their performance in obstetrical emergencies and more specifically postpartum hemorrhage. ${ }^{8}$

There is a need for scientific publications demonstrating the effect of integrating simulation-based learning into the initial midwifery education program. In this study, we evaluated for the first time in Morocco the impact of simulation on the learning of midwifery students, through SBL sessions of both eutocic and dystocic delivery with postpartum hemorrhage.

\section{Patients and Methods}

\section{Sample}

This experience was in the form of high-fidelity simulation sessions organized for student midwives during the 2 nd and 3rd year of their initial training at the higher institute of health sciences (Hassan First University of Settat) Morocco. A total of 31 students received a letter of consent in class by the end of their theoretical course. Only 28 students who consented to participate were allowed to participate in the study, and they were informed that the data collected during the experiment would remain confidential and anonymous. This sample was fully carried out by a $100 \%$ female group whose ages ranged between 19 and 23 years.

\section{Ethics Approval and Informed to Participate}

This paper forms part of the objectives set out in institutional Project FP/2020/02, "Simulation Pedagogy for Nursing and Midwifery Education and Patient Safety" funded by Hassan First University of Settat to support scientific research. This study evaluates a standard education process and is classified as a project for improving the quality of teaching, evaluation and comparison of health education strategies. This study was approved by research committee of Hassan first University and exempt from review by the Ethics Committee.

The data collection was designed following Helsinki's Declaration of ethics. A letter of consent was presented to the students who benefited from this experiment. A letter of consent was presented to the students who benefited from this experiment, only those who consented to participate were allowed to participate in the study, and they were informed that the data collected during the experiment will remain confidential and anonymous.

\section{Methods}

The 28 students were arbitrarily divided into two independent equal groups: experimental and control group (Figure 1). After having completed their theoretical course, the entire sample began the experiment with a pretest to diagnose their knowledge acquired from the theoretical course, then the experimental group benefited from the simulation session with its three stages (briefing, simulation exercise, debriefing), followed by a post-test. While the control group had an opportunity to review and revise the theoretical course, and take a post-test 1 , followed by the simulation session, and finally a post-test 2 .

To sum up, the experimental group passed a total of one pre-test and one post-test, while the control group passed a total of one pre-test and two post-tests (posttest1 and post-test2). The whole group benefited from a second simulation session. During both sessions, evaluation grids were used to assess the technical and nontechnical skills of the learners. The evaluation grids were conceived and developed by ourselves; OC (Master in 


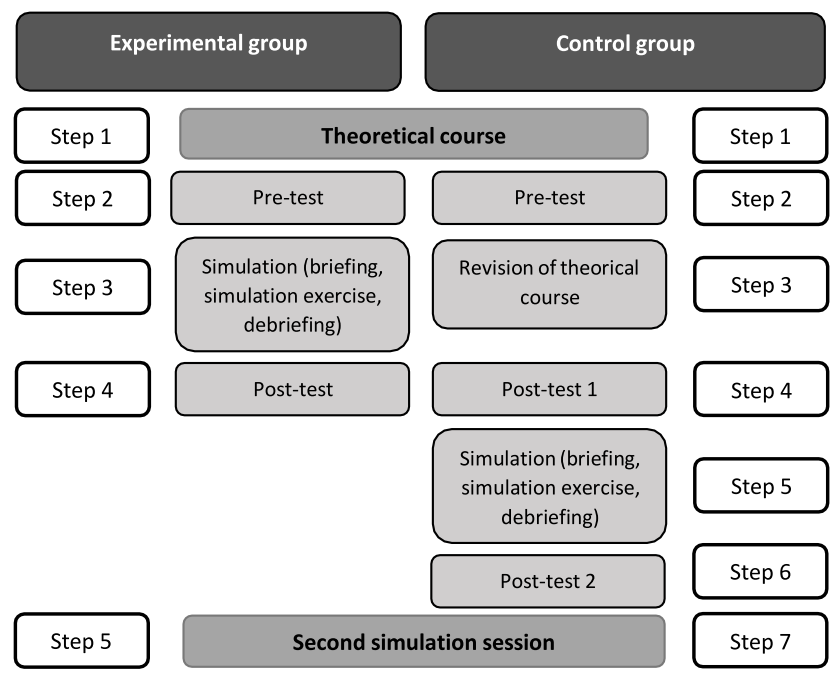

Figure I The steps used in the study design.

midwifery sciences and PhD student) and NM (Master in midwifery sciences and midwifery educator). In the conception of 2nd year grid, we carry out the acts that must be mastered according to the algorithm for the care of a parturient in labor from admission to delivery. While in the 3rd year grid, we used the algorithm for the postpartum hemorrhage care. Adding non-technical skills; such as communication, and teamwork for both grids. We assessed students through these grids by assigning the following scores for each item: i) not done $=0$, ii) not done correctly $=1$, done $=2$. The total score of each grid is 20/20. And during the debriefing which lasted 2 to 3 times the time of the entire session, the learners had an opportunity to express themselves freely. We also used the grid of Yee and his collaborators ${ }^{9}$ which we adapted to our context for non-technical skills. The Yee et al grid includes elements of the four major skills (task management, team working, situation awareness, and decision making) that comprise the Anaesthetists' Non-Technical Skills (ANTS) assessment tool, ${ }^{10}$ each element is anchored for rating with examples of behaviors indicating good and poor practice. There are Four categories: "Good": performance is of a consistently high standard, and the student in this category could be considered as positive example for their colleagues, which can encourage emulation within the group, "Acceptable": a satisfactory performance, "Marginal": performance where considerable improvement is needed, and "Poor category": performance endangered, and serious remediation is required. ${ }^{9}$
The simulation included in this study during the second year of training was an eutocic delivery. And after these students had successfully completed their second year of training, they were given a second experience in their third year. Therefore, we adopted the same design from the previous experiment by dividing the sample into two groups and following the same sequence as described above. But with a different scenario presenting a dystocic delivery with complication of postpartum hemorrhage.

Statistical analyses were carried out using SPSS software (v20). All pair comparisons were performed with the Mann-Whitney test with significant level $\alpha<0.05$.

\section{Results}

Once the two groups were constituted, all participants were examined on their background in normal childbirth courses (second year of training). The experience and control groups obtained 11.87 and 13.27 scores in the pre-test, respectively. Thereafter, in the experience group, students after receiving simulation were required to have high mean score (15.96 \pm $3.78)$ in the post-test compared to the pre-test $(11.87 \pm 3.58)$, which indicates that simulation increased significantly (Mann-Whitney $p<0.001$ ) the students' knowledge. However, in the control group, comparison between scores before and after receiving theoretical revision did not reveal significant difference (Mann-Whitney $p=0.1$ ). Including simulation for students in the control group showed that the mean score shifted significantly (Mann-Whitney $p<0.001$ ) from 13.27 (before simulation) to 18.84 (Table 1).

In the second step of our study all students participating in this training experience were firstly evaluated during the first simulation session using an evaluation grid and

Table I The Mean Score of the Evaluation Tests

\begin{tabular}{|l|l|l|l|l|}
\hline \multicolumn{2}{|c|}{} & $\begin{array}{l}\text { Pre-Test } \\
\text { Mean } \\
\text { Score } \\
\mathbf{\pm S D}\end{array}$ & $\begin{array}{l}\text { Post-Test } \\
\text { I Mean } \\
\text { Score } \\
\mathbf{\pm S D}\end{array}$ & $\begin{array}{l}\text { Pre-Test 2 } \\
\text { Mean } \\
\text { Score } \\
\mathbf{\pm S D}\end{array}$ \\
\hline $\begin{array}{l}\text { Normal } \\
\text { childbirth } \\
\text { (2nd year) }\end{array}$ & $\begin{array}{l}\text { Experience } \\
\text { Group }\end{array}$ & $11.87 \pm 3.58$ & - & $\begin{array}{l}15.96 \\
\pm 3.78^{* * * *}\end{array}$ \\
\cline { 2 - 5 } & $\begin{array}{l}\text { Control } \\
\text { group }\end{array}$ & $13.27 \pm 2.76$ & $13.5 \pm 2.22$ & $\begin{array}{l}18.84 \\
\pm 1.78^{* * *}\end{array}$ \\
\hline $\begin{array}{l}\text { Postpartum } \\
\text { hemorrhage } \\
\text { (3rd year) }\end{array}$ & $\begin{array}{l}\text { Experience } \\
\text { Group }\end{array}$ & $11.5 \pm 4.44$ & - & $\begin{array}{l}18.29 \\
\pm 4.47^{* * * *}\end{array}$ \\
\cline { 2 - 5 } & $\begin{array}{l}\text { Control } \\
\text { group }\end{array}$ & $12.46 \pm 2.99$ & $12.95 \pm 1.59$ & $\begin{array}{l}18.18 \\
\pm 1.75^{* * * *}\end{array}$ \\
\hline
\end{tabular}

Note: ${ }^{* * *} p$-value $<0.001$. 
then enrolled in a second simulation session where they were re-evaluated. The evaluation grid mean obtained from the first simulation session (11.23) was significantly (Mann-Whitney $p<0.001$ ) shifted to 19.69 after the second simulation session. During the debriefing phase, the realism of the sessions was considered satisfactory by the students who expressed their total motivation and immersion in the simulated situation, which caused stress in some of them. The students felt a certain responsibility during the simulation session, which pushed them to mobilize and put all their theoretical knowledge into practice and act according to their own initiative, a self-assessment was initiated during the debriefing, which allows to increase self-confidence, to find out about the encountered gaps and pitfalls so as to deal with them on the spot and thus improve their way of doing things. In addition, in order to more understand the impact of the simulation on the non-technical skills, we also carried out a qualitative analysis of data obtained during the debriefing phase using the Yee's grid. ${ }^{9}$ We found that there was no student in the "poor category". Nine students were classified as "marginal". Fourteen students were in the "acceptable category". Five students had high score indicating "good category".

One year later (third year of training), we enrolled the same students in a second experience (postpartum hemorrhage) respecting the same protocol used in the first experience (second year of training). The experience and control groups obtained 11.5 and 12.46 scores, respectively. After being involved in a simulation, students in the experience group were observed to have high mean score in the post-test $(18.29 \pm 4.47)$ compared to the pre-test $(11.5 \pm 4.44)$ which indicates that in simulation situation the students significantly increased their knowledge, (Mann-Whitney $p<0.001)$. However, in the control group, comparison between scores before and after receiving theoretical revision did not reveal any significant difference (Mann-Whitney $p=$ 0.2). But involving students of the control group in simulative situations showed that the mean score shifted significantly (Mann-Whitney $p<0.001$ ) from 12.46 (before simulation) to 18.18 (after simulation) (Table 1).

The evaluation grid mean obtained from the second simulation session was significantly (Mann-Whitney $p<0.001)$ increased from the 9.12 in the first simulation session to 19.4 in the second simulation session. During the debriefing phase, the students expressed themselves freely, and there was there was a fruitful discussion between the learners and the trainers. The positive impact of the simulation was observed on the day of the repetition and we noticed that both the technical and non-technical practices allowed wide improvement in scores and selfconfidence for the benefit of the students. The feeling of competence acquisition took place as more logical reasoning and regulation have been deployed. In addition, a qualitative analysis was carried out during the debriefing phase using the Yee's grid. ${ }^{9}$ We found that there was no student in the "poor category". Two students were classified as "marginal". Twenty-two students were in the "acceptable category". Four students had high score indicating "good category".

\section{Discussion}

Student midwives should strongly acquire the necessary skills in normal and complex childbirth during their initial training. ${ }^{11}$ In addition, an appropriate midwifery education should be instaured so that a competent teaching staff can teach students how to translate theory into practice. ${ }^{12}$ The present study showed for the first time in Morocco that the use of simulation based-learning as a teaching strategy in the eutocic and dystocic delivery is beneficial for midwifery students in their second and third years of initial training. Post-test scores after simulation were higher than pre-test and post-test scores before simulation, corroborating previous research findings confirmed the increase in knowledge with the integration of simulation into the learning curriculum. ${ }^{13}$

Debriefing session is an integral and very important part of every SBL experience. Debriefing time is two to three times the time of the entire simulation session. During this phase stress is reported by most participants. They added that they would be more comfortable because of the self-confidence they gained from the first simulation experience. It can be said that the simulation significantly increased students' confidence. ${ }^{14}$

On the other hand, the increase in student midwives' knowledge, as demonstrated by the post-test results after the simulation, was characterized by skill improvements, as demonstrated by the evaluation grid results, especially in the second rehearsal session, This is consistent with Nelissen et al in their study where they measured the level of knowledge and skills before and immediately after simulation-based training in obstetrical care to understand the impact of training on these components. ${ }^{15}$ The results of the study revealed that the simulation is based on the concept of the right to error. $100 \%$ of the third year students failed to save the parturient, having postpartum 
hemorrhage, in the first day of the simulation, due to errors and lack of skill that could be detected through the evaluation grids. Which is not tolerable in reality but they made up for it during the rehearsal session. This finding shows the interest of repetition as well as its added value in terms of knowledge and technical and nontechnical skills. Simulation allowed the students to learn from their mistakes, what is called error pedagogy where the error is acceptable or even desirable, because it provides the students with an opportunity to learn from their mistakes. This idea has been affirmed by Roh and his team, who reported in their study that integrating problembased learning with simulation enhances student performance. $^{16}$

Previous studies have shown that traditional clinical experiences often do not provide students with the opportunity to care for patients in crisis, or to develop independent decision-making and communication skills. ${ }^{17}$ In this sense, high-fidelity simulation provides an opportunity for learners to be immersed in a more realistic environment that allows for the development of students' clinical reasoning. This is illustrated by our experience using high-fidelity simulation in the clinical management of postpartum hemorrhage.

To our knowledge, this is the first research paper in Morocco to demonstrate the impact of simulation basedlearning on the initial training of midwives. The restricted number of identified and included participants $(n=28)$ can be seen as a limitation. The time interval between the first experience of simulation of normal delivery was one year compared to the second experience of simulation of dystocic delivery with postpartum hemorrhage may also be another limitation of the study. This research paper can be used to open up new avenues of research in this area.

\section{Conclusion}

SBL has been the missing link in the learning and teaching pedagogy. The initial learning phase for students is characterized by the committing of errors that provide a golden opportunity for learning. Through this experiment, we discovered that SBL situations are as close to reality as possible than any other approach, proceeding from the normal context to more complex. It has been thoroughly demonstrated as being an essential tool that allows students to acquire technical and non-technical skills, and improve their knowledge in a safe environment.

In conclusion and as far as we are concerned, SBL remains one of the leading methods that should be integrated into the pedagogical programs of the midwife's initial training.

\section{Abbreviations}

SBL, simulation-based learning; MDGs, Millennium Development Goals.

\section{Data Sharing Statement}

The datasets used and/or analysed during the current study are available from the corresponding author on reasonable request.

\section{Consent for Publication}

Informed written consent to take part in the research have been obtained prior to the commencement of the study, and participant data have been anonymised.

\section{Acknowledgments}

We thank Professor Mohamed Belabchiri for his active involvement in the English language revision of the article. We thank all the midwifery students of the higher institute of health sciences, Settat, Morocco, who have demonstrated their involvement and commitment during the experience. We would like to thank the National Center for Scientific and Technical Research (CNRST), Rabat, Morocco.

\section{Funding}

This study was funded by University Hassan first's own fund [grant number FP/2020/02]. The funding body had no involvement in the design of the study, the data collection, the analyses and interpretation or the manuscript preparation.

\section{Disclosure}

The authors report no conflicts of interest in this work.

\section{References}

1. Koblinsky M, Moyer CA, Calvert C, et al. Quality maternity care for every woman, everywhere: a call to action. Lancet. 2016;388 (10057):2307-2320. doi:10.1016/S0140-6736(16)31333-2

2. Sebbani M, Adarmouch L, Amine M, Cherkaoui M. Mobilisation communautaire pour l'amélioration de la surveillance de la grossesse en milieu rural au Maroc. Pan African Med J. 2020;35:73. doi:10.11604/pamj.35.73.18328

3. Harder N, Turner S. Applying simulation design criteria to non-manikin-based experiences: a modified shadowbox technique. Nurs Educ Perspect. 2020;41(1):59-60. doi:10.1097/01. NEP.0000000000000424

4. Meakim C, Boese T, Decker S, et al. Standards of best practice: simulation standard I: terminology. Clin Simul Nurs. 2013;9(6):S3S11. doi:10.1016/j.ecns.2013.04.001 
5. Society for Simulation in Healthcare. About simulation; 2021. Available from: https://www.ssih.org/About-SSH/About-Simulation. Accessed December 17, 2020.

6. Bogren M, Rosengren J, Erlandsson K, Berg M. Build professional competence and Equip with strategies to empower midwifery students - an interview study evaluating a simulation-based learning course for midwifery educators in Bangladesh. Nurse Educ Pract. 2019;35:27-31. doi:10.1016/j.nepr.2019.01.002

7. Sarfati L, Ranchon F, Vantard N, et al. Human-simulation-based learning to prevent medication error: a systematic review. J Eval Clin Pract. 2019;25(1):11-20. doi:10.1111/jep.12883

8. Burns ES, Duff M, Leggett J, Schmied V. Emergency scenarios in maternity: an exploratory study of a midwifery and medical student simulation-based learning collaboration. Women Birth. 2020. doi:10.1016/j.wombi.2020.10.005

9. Yee B, Naik VN, Joo HS, et al. Nontechnical skills in anesthesia crisis management with repeated exposure to simulation-based education. Anesthesiology. 2005;103(2):241-248. doi:10.1097/ 00000542-200508000-00006

10. Fletcher G, Flin R, McGeorge P, Glavin R, Maran N, Patey R. Anaesthetists' Non-Technical Skills (ANTS): evaluation of a behavioural marker system. Br J Anaesth. 2003;90(5):580-588. doi:10.1093/bja/aeg112

11. Ildan Çalım S, Cambaz Ulaş S, Demirci H, Tayhan E. Effect of simulation training on students' childbirth skills and satisfaction in Turkey. Nurse Educ Pract. 2020;46:102808. doi:10.1016/j. nepr.2020.102808
12. Morrow J, Biggs L, Stelfox S, Phillips D, McKellar L, McLachlan H. Evaluating a standardised clinical assessment tool for pre-registration midwifery students: a cross-sectional survey of midwifery students and midwives in Australia. Women Birth. 2016;29(1):85-92. doi:10.1016/j.wombi.2015.09.001

13. Rode JL, Callihan ML, Barnes BL. Assessing the value of large-group simulation in the classroom. Clin Simul Nurs. 2016;12 (7):251-259. doi:10.1016/j.ecns.2016.02.012

14. Brown J, Kelly MA, McGough S, et al. The impact of simulation on graduate entry master's students' confidence to provide safe patient care: a longitudinal study. Clin Simul Nurs. 2020;45:6-15. doi:10.1016/j.ecns.2019.12.001.

15. Nelissen E, Ersdal H, Mduma E, et al. Helping mothers survive bleeding after birth: retention of knowledge, skills, and confidence nine months after obstetric simulation-based training. $B M C$ Pregnancy Childbirth. 2015;15(1):190. doi:10.1186/s12884-0150612-2

16. Roh YS, Kim SS, Kim SH. Effects of an integrated problem-based learning and simulation course for nursing students. Nurs Health Sci. 2014;16(1):91-96. doi:10.1111/nhs.12069

17. McCalla-Graham JA, Gagne JCD. The lived experience of new graduate nurses working in an acute care setting. J Contin Educ Nurs. 2015;46(3):122-128. doi:10.3928/00220124-20150220-17

\section{Publish your work in this journal}

Advances in Medical Education and Practice is an international, peerreviewed, open access journal that aims to present and publish research on Medical Education covering medical, dental, nursing and allied health care professional education. The journal covers undergraduate education, postgraduate training and continuing medical education including emerging trends and innovative models linking education, research, and health care services. The manuscript management system is completely online and includes a very quick and fair peer-review system. Visit http://www.dovepress.com/testimonials.php to read real quotes from published authors. 